\title{
BMJ Open Concurrent validity, discriminatory power and feasibility of the instrument for Identification of Parents At Risk for child Abuse and Neglect (IPARAN)
}

\author{
Esther M B Horrevorts, ${ }^{1}$ Amy van Grieken, ${ }^{1}$ Cathelijne L Mieloo, ${ }^{1,2}$ \\ Esther Hafkamp-de Groen, ${ }^{3}$ Rienke Bannink, ${ }^{1}$ \\ Merian B R Bouwmeester-Landweer, ${ }^{4}$ Suzanne Broeren, ${ }^{1}$ Hein Raat $^{1}$
}

To cite: Horrevorts EMB, van Grieken A, Mieloo CL, et al. Concurrent validity, discriminatory power and feasibility of the instrument for Identification of Parents At Risk for child Abuse and Neglect (IPARAN). BMJ Open 2017;7:e016140. doi:10.1136/ bmjopen-2017-016140

- Prepublication history and additional material for this paper are available online. To view these files please visit the journal online (http://dx.doi. org/10.1136/bmjopen-2017016140).

Received 26 January 2017 Revised 20 June 2017 Accepted 29 June 2017

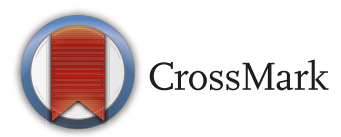

${ }^{1}$ Department of Public Health, Erasmus MC University

Medical Center, Rotterdam, The Netherlands

${ }^{2}$ Municipality of Rotterdam, Rotterdam, The Netherlands

${ }^{3}$ Vereniging Stevig Ouderschap, Oudewater, The Netherlands

${ }^{4}$ Rivas Zorggroep, Gorinchem, The Netherlands

Correspondence to

Esther M B Horrevorts;

e.horrevorts@erasmusmc.nl

\section{ABSTRACT}

Objectives To determine the feasibility, concurrent validity and discriminatory power of the instrument for Identification of Parents At Risk for child Abuse and Neglect (IPARAN) among Dutch parents with a newborn child.

Setting Community paediatrics.

Participants Data from a controlled trial were used. In total, 2659 Dutch parents with a newborn child were invited to participate. Of the 2659 parents, 759 parents filled in the consent form and participated in the study. Primary and secondary outcome measures Concurrent validity was determined by calculating correlations—using the Pearson's correlation (r) - between the IPARAN score and related constructs from the following instruments: the Empowerment Questionnaire 2.0, the Family Functioning Questionnaire and the Parenting Stress Questionnaire. Discriminatory power was determined by calculating receiver operating characteristic (ROC) curves between high-risk mothers and low-risk mothers according to their scores on the related constructs. Feasibility was determined by examining the percentage of missing answers.

Results In terms of concurrent validity, we found that 3 out of 12 correlations between the IPARAN score and related constructs were strong (ie, $r>0.50$ ) and 4 out of 12 were medium (ie, $r=0.30-0.49$ ). In terms of discriminatory power, mothers with a score in the borderline/clinical range or lowest 10 percent $(\mathrm{P} 10)$ range of the related constructs (high-risk mothers) had a higher IPARAN score than mothers with a score in the normal range or highest 90 percent $(\mathrm{P} 90)$ range of the related constructs (low-risk mothers). Effect sizes varied from $d=0.37$ to $d=1.93$, and the area under the ROC curve varied from 0.62 to 0.93 . Regarding feasibility, the part of the IPARAN filled in by the mother had on average $0.7 \%$ missing answers, whereas the part of the IPARAN filled in by the father had on average $1.7 \%$ missing answers.

Conclusion The results of this study support the concurrent validity, discriminatory power and feasibility of the IPARAN among a population of Dutch parents with a newborn child.

\section{INTRODUCTION}

Research has shown that parents/caregivers (further mentioned parents) have many
Strengths and limitations of this study

- First study to validate the risk assessment tool 'instrument for Identification of Parents at Risk for child Abuse and Neglect' to identify parents at-risk of parenting stress.

- Various reference scales of risk factors for parenting stress were used for validation.

- A convenient sampling method was used.

- Not all risk factors of parenting stress could be validated.

- The sample consisted of highly educated respondents.

concerns about parenting in general, developmental delay or behaviour of their child, especially when their child is still young. Almost $60 \%$ of parents with children around 14 months of age indicated to have some parental concerns for which they felt they needed assistance or advice from someone outside the family, and $11.4 \%$ indicated to have frequent concerns. ${ }^{1}$ Circumstances in parents' life may cause parenting to become more challenging and stressful, ${ }^{2}$ and lead to parenting stress. Parenting stress is conceptualised by Östberg ${ }^{3}$ as a perceived discrepancy between situational demands and personal resources in parenthood. Previous research has identified circumstances that predict the risk of parenting stress. These predictors can be categorised into different categories: competence as a person/parent (eg, ambivalent feelings about parenthood, the tendency to become upset and angry, believing in physical punishment and spousal violence ${ }^{4-9}$ ), parental developmental history (eg, alcohol/drug abuse, negative childhood experiences and negative sexual experiences ${ }^{4-7}{ }^{10-13}$ ), partner support (eg, being a single parent $\left.{ }^{14}\right)$, social network (eg, the lack of social support ${ }^{46}$ ), depressive 
symptoms (eg, depressive feelings ${ }^{4}{ }^{11}$ ) and demographic factors (eg, young parenthood, low birth weight of the child and gestational age $\mathrm{e}^{46111415}$ ).

Parenting stress is associated with negative parenting practices such as child abuse and neglect. ${ }^{16}$ Child abuse and neglect, in turn, is associated with adverse physical, cognitive and psychosocial outcomes for children in the short term and long term. ${ }^{17-19}$ Research of Mills et al ${ }^{17}$ showed that child abuse and neglect of children was independently associated with impaired cognition and academic functioning in adolescence. Child maltreatment was also related to a range of mental disorders, drug use, suicide and risky sexual behaviour, ${ }^{18}$ and also associated to negative physical outcomes such as risk for diabetes, lung disease, malnutrition and vision problems. ${ }^{19}$

It is important to provide help and support to parents that experience parenting stress. However, it remains a challenge to identify parents at-risk of parenting stress timely, in order to provide preventive interventions. The instrument for Identification of Parents at Risk for child Abuse and Neglect (IPARAN) ${ }^{20}$ was developed to identify parents with a newborn child who are likely to experience parenting stress that may be associated with child abuse or neglect, in order to provide them with a preventive intervention, such as the Supportive Parenting Intervention. ${ }^{21}$ By identifying those parents at-risk of parenting stress early on in a child's life, by screening parents with a newborn child, we may be better able to support these parents. This helps to prevent the long-term potential harmful effects of parenting stress and the associated negative parenting practices such as child abuse and neglect.

The IPARAN focuses on the aforementioned predictors that increase the risk of parenting stress, such as the parental developmental history, social network and depressive symptoms. The IPARAN is currently used by $51 \%$ of Youth Health Care (YHC) centres in the Netherlands to support professionals in their assessment of risk of parenting stress. ${ }^{22}{ }^{23}$ Although some research has been conducted regarding non-response,$^{24}$ there is no study yet available examining the concurrent validity, discriminatory power and feasibility of the IPARAN. Information on the validity and feasibility of the IPARAN can support YHC and local policy to make a careful decision in the methodologies that are used in daily practice to detect at-risk families. The use of a valid and feasible instrument supports detection of at-risk families in a timely manner, and thus the possibility to offer these families suitable interventions. The IPARAN focuses on predictors of parenting stress. In this study, we investigated whether (a) the items/constructs of the IPARAN are in accordance with other validated instruments aimed at predictors of parenting stress (ie, concurrent validity), (b) the IPARAN distinguished between parents at-risk and parents not at risk of parenting stress, (ie, discriminatory power) and (c) the IPARAN was easy to use (feasibility).

The objective of this study was therefore to evaluate the concurrent validity, discriminatory power and feasibility of the IPARAN in a population of Dutch parents with a newborn child. Our research question was as follows: Is the IPARAN a valid and feasible tool for assessing risk factors for parenting stress in this population? To answer this question, we calculated correlations between parents' scores on the IPARAN and those on related constructs (concurrent validity). Based on the direction of the questions asked, we expected negative correlations for all related constructs, except for the related construct 'depressive symptoms'. Additionally, to explore the discriminatory power of the IPARAN, differences in IPARAN score between mothers within the borderline/clinical range or P10 range of the related constructs (high-risk mothers) and mothers within the normal range or P90 range of the related constructs (low-risk mothers) were examined, and receiver operating characteristic (ROC) curves were calculated. We expected higher IPARAN scores for the high-risk mothers. The feasibility of the IPARAN was determined by examining the percentage of missing answers.

\section{METHODS}

\section{Data collection and participants}

This study used data from the Supportive Parenting study, a controlled trial described in detail elsewhere. ${ }^{25}$ The IPARAN was previously named 'Supportive Parenting Questionnaire $^{25}$ (trial registration: www.trialregister. nl; Netherlands Trial Register: NTR 5307; 16 July 2015; Stage: Results).

In short, all parents with a child born between January and September 2014, living in a suburban area of the western part of the Netherlands were invited to participate. In order to participate, parents were required to have at least basic Dutch language skills and provide written informed consent.

In the Netherlands, a YHC nurse visits all parents with a newborn child at home 5-14 days after childbirth. This is known as the 'well-child visit'. During this visit, the YHC nurse informed the parents about the study and provided parents with an information leaflet, informed consent form and baseline questionnaire. This baseline questionnaire included the IPARAN and three other questionnaires that assess related constructs, namely the Empowerment Questionnaire 2.0 (EMPO 2.0), ${ }^{26}$ the Family Functioning Questionnaire $(\mathrm{FFQ})^{27}$ and the Parenting Stress Questionnaire (PSQ) ${ }^{28}$ Parents were invited to provide written informed consent for participation in the study and to return the baseline questionnaire to the researchers in a prepaid envelope.

In total, 2659 parents received information about the study and were invited to participate. Of these, 759 parents completed the written informed consent form and baseline questionnaire (28.5\%). However, for 32 families $(4.2 \%)$, an IPARAN score could not be calculated for the father. Only the mothers completed their part and not both parents, despite the mother indicating that she lived together with her husband or partner, leaving a population for analysis of 727 parents. 
Table 1 Demographic characteristics of the study sample

\begin{tabular}{|c|c|c|c|c|c|}
\hline Subject & Characteristics & Total $(n=727)$ & $\begin{array}{l}\text { Parents at-risk } \\
(\mathrm{n}=177)\end{array}$ & $\begin{array}{l}\text { Parents not at- } \\
\text { risk }(n=550)\end{array}$ & p Value \\
\hline \multirow[t]{3}{*}{ Mother } & Mean age (SD), years & $30.0(4.5)$ & $30.7(5.3)$ & $29.8(4.2)$ & 0.048 \\
\hline & Nationality (Dutch, \%) & 96.7 & 93.2 & 97.8 & 0.003 \\
\hline & Educational level (low, \%) & 7.4 & 13.2 & 5.5 & 0.002 \\
\hline \multirow{4}{*}{ Father } & $<19$ years $(\%)$ & 0.0 & 0.0 & 0.0 & - \\
\hline & Nationality (Dutch, \%) & 97.6 & 94.7 & 98.5 & 0.004 \\
\hline & Educational level (low, \%) & 13.6 & 13.1 & 13.8 & 0.962 \\
\hline & IPARAN score & $1.02(1.33)$ & $2.51(1.63)$ & $0.58(0.81)$ & $<0.001$ \\
\hline Child & Birth weight $(<2500 \mathrm{~g}, \%)$ & 5.2 & 11.3 & 3.3 & $<0.001$ \\
\hline \multirow[t]{2}{*}{ Household } & Family composition (single parent, \%) & 1.7 & 5.1 & 0.5 & $<0.001$ \\
\hline & Net monthly family income $(<€ 1800,-\%)$ & 10.9 & 15.5 & 9.4 & 0.024 \\
\hline Other & Gender of parent* (female, \%) & 93.0 & 92.7 & 93.1 & 0.844 \\
\hline
\end{tabular}

${ }^{*}$ Gender of the parent who completed the remaining part of the baseline questionnaire.

Bold numbers indicate a significant difference between parents at-risk and parents not at-risk $(\mathrm{p}<0.05)$ as tested with an independent $t$-test or chi-square test.

IPARAN, instrument for Identification of Parents at Risk for child Abuse and Neglect.

\section{Sample characteristics}

Table 1 shows the demographic characteristics of the sample. The majority of the children in the total sample is boys $(52.2 \%)$ and the mean age of the children is 5.2 months. The parents are mainly of Dutch nationality (96.7\% of the mothers and $97.6 \%$ of the fathers), with a middle to high educational level. The majority of the sample consists of a two-parent family (98.3\%), with a net monthly income of $\geq € 1800,-(89.1 \%)$.

\section{Ethical statement}

Methods were carried out in accordance with the Strengthening the Reporting of Observational Studies in Epidemiology statement. ${ }^{29}$ Parents received written information about the study and were free to refuse participation. Parents willing to participate provided written informed consent. Only anonymous data were used for analysis. This study was approved by the Medical Ethics Committee of Erasmus Medical Center Rotterdam (MEC-2013-568).

\section{Measurements}

The instrument for Identification of Parents at Risk for child Abuse and Neglect

The IPARAN aims to identify risk factors related to the development of parenting stress. ${ }^{30}$ These risk factors were selected by Bouwmeester-Landweer $e t a l^{11}$ based on previous research ${ }^{4-15}$ and can be divided into three domains ${ }^{31}$ based on the ecological model of Belsky, ${ }^{32-34}$ and the concept of parental awareness of Newberger, ${ }^{35}$ elaborated on by Baartman. ${ }^{36}$ These three domains are as follows: child and family characteristics, parental developmental history and personality (including parental awareness) and characteristics of the social context.

The IPARAN is a three-page self-report form, containing 37 items in total. The IPARAN has a general part (filled in by both parents), a part for the mother and a part for the father/other parent (see online supplementary table S1). The general part consists of five items relating to risk factors in the first domain: birth weight of the child, duration of pregnancy, age of mother at delivery, age of father at delivery and family structure. The part filled in by the mother and the part filled in by the father/other parent each consists of 16 items. These items relate to risk factors in all three domains. The item within the domain of child and family characteristics is 'quarrels with partner ever become physical'. Items within the domain of parental developmental history and personality (including parental awareness) are 'worried about raising your child', 'unhappy during pregnancy about becoming a mother/father', 'parents or carers had loving relationship', 'being hit as a child', 'ever felt unhappy in past 3 years', 'losing temper', 'negative sexual experience', 'drug/alcohol abuse' and 'hitting should be part of upbringing'. Items within the domain of characteristics of the social context are 'finding it difficult to ask for help', 'feeling comfortable in neighbourhood', 'maintain close 
relations with family', 'receiving support from network of family, neighbours, friends' and 'receiving support from partner'. The items are accompanied by either a fourpoint response scale (always, often, sometimes, never) or a yes/no option.

Each item is assigned a score between 0 and 2 (see online supplementary table S1). In order to categorise parents as either being at-risk or not at-risk for parenting stress, a summation score is calculated for each parent by adding the total score of the parent to the total score of the general part of the instrument. If either parent has a summation score of $\geq 3$, the family is considered to be at risk of parenting stress. The cut-off score of $\geq 3$ is based on previous research, ${ }^{31}$ and minimises the chances of overestimation and underestimation of parents at risk of parenting stress.

\section{Demographic characteristics}

Data were collected on age, gender and country of birth of both parents and child. Educational level of both parents and net family income per month were also included. Educational level was classified as low (primary education, lower secondary education), middle (higher secondary education, vocational education) or high (higher vocational education, university). Net family income was classified as low ( $<€ 1800$,- per month) or high ( $\geq € 1800$,- per month). Nationality of the child, father and mother was classified as Dutch or non-Dutch, according to definitions used by Statistics Netherlands. ${ }^{37}$

\section{Competences as a person and parent}

Competences as a person and parent were assessed by two subscales of the EMPO 2.0, ${ }^{26}$ a questionnaire that assesses parental empowerment. Competence as a person refers to parents' feelings about whether they are in control of their own lives and capable of dealing with problems as they occur. This construct is assessed by eight items. An example of an item is 'I can handle problems easily'. Competence as a parent is about parents' feelings whether they are in control of their child and know their strengths and limitations as a parent. This construct is assessed by seven items. An example of an item is 'I have great confidence in my parenting skills'. Both subscales have a five-point response scale ranging from $1=$ strongly disagree to $5=$ strongly agree.

For both subscales raw scores are converted to a score between 1 (indicating a low level of competence) and 10 (indicating a high level of competence). Depending on the amount of items belonging to a subscale (eg, competence as a person consists of eight items), a minimum score, 8 , and maximum score, 40 , can be calculated. The maximum score minus the minimum score of a subscale $(40-8=32)$ is distributed evenly over the maximum converted score of $10(10 / 32=0.3125)$. To calculate a parent's converted score, the minimum score of the subscale is subtracted from his/her summation score, for example, $32((32-8) * 0.3125=7.5)$. Parents within the first $10 \%$ (P10) of both subscales were seen as high-risk parents. The subscales competence as a person and competence as a parent have a Cronbach's alpha of 0.85 and 0.79 , respectively. ${ }^{26}$

\section{Parental developmental history}

Parental developmental history is assessed by the subscale childhood experience, derived from the $\mathrm{FFQ}^{27}$ a questionnaire that assesses problems parents encounter within their family. Childhood experience is about a parent's own childhood and whether he/she has pleasant memories of his/her own childhood. The subscale is assessed by four items on a four-point response scale ranging from $1=$ not true to $4=$ very true. A summation score is calculated and also converted into a category (normal, borderline, clinical) according to the guideline. ${ }^{27}$ An example of an item is 'you feel your own parents treated you well'. This subscale has a Cronbach's alpha of $0.85 .{ }^{27}$ The FFQ provides norm referenced standard scores for children between $0-3,4-11$ and $12-18$ years.

\section{Partner support}

Partner support is assessed by the subscale partner relationship, also derived from the $\mathrm{FFQ}^{27}$ and is about the perception of a person's relationship with his/her partner and the extent to which he/she feels supported by his/ her partner. Partner relationship is assessed by five items on a four-point response scale ranging from $1=$ not true to $4=$ very true. A summation score is calculated and also converted into a category (normal, borderline, clinical) according to the guideline. ${ }^{27}$ An example of an item is 'you feel your partner supports you in raising the children'. This subscale has a Cronbach's alpha of $0.89 .{ }^{27}$

\section{Social network}

Social network is assessed by the subscale social contacts, also derived from the FFQ ${ }^{27}$ The subscale social contacts refers to the extent to which a parent has contact with neighbours, family and friends and is assessed by five items on a four-point scale ranging from $1=$ not true to $4=$ very true. A summation score is calculated and also converted into a category (normal, borderline, clinical) according to the guideline. ${ }^{27}$ An example of an item is 'your family has regular contact with other local residents'. This subscale has a Cronbach's alpha of $0.74 .^{27}$

\section{Depressive symptoms}

Symptoms of depression was assessed with the subscale depressive symptoms, derived from the $\mathrm{PSQ}^{28}$ a questionnaire that assesses the level of stress parents experience in their role as a parent. This subscale refers to the extent to which a parent is happy with him/herself and his/her circumstances and is assessed by seven items on a four-point response scale ranging from $1=$ not true to $4=$ very true. A summation score is calculated and also converted into a category (normal, borderline, clinical) according to the guideline. ${ }^{28}$ An example of an item is 'sometimes I do not see the point of living'. This subscale has a Cronbach's alpha of $0.86 .^{28}$ The PSQ provides norm 
referenced standard scores for children between 0-3, 4-11 and 12-18years.

\section{Statistical analyses}

Concurrent validity

Concurrent validity was assessed by correlating the IPARAN score with those obtained for the related constructs of the EMPO 2.0, ${ }^{26}$ the $\mathrm{FFQ}^{27}$ and the $\mathrm{PSQ}^{28}$ and calculating Pearson's correlation coefficient ( $\mathrm{r}$ ). The IPARAN score of the mother was only correlated with the scores obtained for the related constructs, filled in by the mother. The IPARAN score of the father was only correlated with the scores obtained for the related constructs, filled in by the father. We used the criteria suggested by Cohen for judging the size of the correlations thus obtained: $r<0.30$ for minor, $r=0.30-0.49$ for medium and $r \geq 0.50$ for strong correlations. ${ }^{38}$

\section{Discriminatory power}

An independent t-test was used to compare the IPARAN score of mothers with a borderline/clinical range or P10 range of the related constructs (high-risk mothers) with those for mothers with a score in the normal range or P90 range of the related constructs (low-risk mothers). In order to relate the difference in mean scores to the distribution of the scores, effect size estimations (d) were calculated by dividing the difference between the mean scores by the $\mathrm{SD}$. We used the criteria suggested by Cohen for judging the effect sizes; thus, obtained: $d=0.20$ for small, $\mathrm{d}=0.50$ for moderate and $\mathrm{d}=0.80$ for large effect sizes. ${ }^{38}$ Additionally, ROC curves were plotted and the area under the curve (AUC) was calculated. The greater the AUC, the greater the discriminatory power of the IPARAN for discriminating between high-risk mothers and low-risk mothers. An AUC $<0.50$ indicated chance level; $0.50 \leq \mathrm{AUC}<0.70$ indicated low discriminatory power; $0.70 \leq \mathrm{AUC}<0.90$ indicated moderate discriminatory power an AUC $\geq 0.90$ indicated high discriminatory power. $^{39}$

\section{Feasibility}

To determine feasibility, percentages of missing answers at the item level of the IPARAN were calculated. Percentages of respondents for whom it was not possible to calculate a total IPARAN score due to missing items were also calculated.

Furthermore, descriptive statistics were used to describe the study sample. Only complete cases were used for all analyses. All analyses were performed using SPSS V.21. ${ }^{40}$ To correct for multiple comparisons, a Bonferroni correction was used. The results in tables 2 and 3 are presented with correction for multiple comparisons.

\section{RESULTS \\ Comparison of risk and non-risk groups in demographic variables}

Table 1 shows the demographic characteristics of parents at risk and parents not at risk. In the subgroup parents at-risk, mothers were on average older, were more often of non-Dutch ethnicity and had a lower educational level compared with mothers in the subgroup parents not at risk. Fathers in the subgroup parents at risk were more often of non-Dutch ethnicity compared with fathers in the subgroup parents not at risk. Children in the subgroup parents at risk were more often a boy, were on average of lower gestational age, and had a lower birth weight, compared with children in the subgroup parents not at risk. The subgroup parents at-risk were more often a

Table 2 Concurrent validity: correlations between parents' scores (mothers $n=676$; fathers $n=51$ ) on the IPARAN and those on the related constructs

\begin{tabular}{|c|c|c|c|c|c|c|}
\hline \multirow[b]{2}{*}{ IPARAN* } & \multirow[b]{2}{*}{ Related constructs } & \multirow{2}{*}{$\begin{array}{l}\text { Missings } \\
\mathrm{n}\end{array}$} & \multicolumn{2}{|c|}{ Correlation mother's part } & \multicolumn{2}{|c|}{ Correlation father's part } \\
\hline & & & $\mathbf{r}$ & $\mathbf{p}$ & $\mathbf{r}$ & $\mathbf{p}$ \\
\hline \multirow[t]{4}{*}{ Total score } & Competence as a personף† & 4 & -0.24 & $<0.001$ & -0.40 & 0.004 \\
\hline & Childhood experienceף‡ & 2 & -0.58 & $<0.001$ & -0.59 & $<0.001$ \\
\hline & Partner relationship $\ddagger$ & 18 & -0.36 & $<0.001$ & -0.17 & 0.236 \\
\hline & Depressive symptoms ${ }^{\star \star} \S$ & 4 & 0.50 & $<0.001$ & 0.48 & $<0.001$ \\
\hline
\end{tabular}

Bold numbers indicate a significant correlation between the item on the IPARAN and the related construct $(p<0.008)$ as tested with Pearson's correlation and corrected for multiple testing with a Bonferroni correction $(0.05 / 6)$.

${ }^{*}$ Correlations between total score on the IPARAN in the first column and the related constructs in the second column were calculated using Pearson's correlation coefficient ( $r$ ). The IPARAN score of the mother was correlated to related constructs filled in by the mother. The IPARAN score of the father was correlated to related constructs filled in by the father.

†Derived from the EMPO 2.0. ${ }^{26}$

fDerived from the Family Functioning Questionnaire. ${ }^{27}$

§Derived from the Parenting Stress Questionnaire. ${ }^{28}$

IA low score indicates problems.

${ }^{\star \star} A$ high scores indicates problems.

EMPO 2.0, Empowerment Questionnaire 2.0; IPARAN, instrument for lentification of Parents at Risk for child Abuse and Neglect. 
Table 3 Discriminatory power of the mothers' IPARAN score, relative to the scores on the related constructs in the borderline/ clinical or P10 range filled in by the mothers

\begin{tabular}{|c|c|c|c|c|}
\hline Related constructs & $\mathbf{n}$ & Mean score on IPARAN ${ }^{\star}$ (SD) & Cohen's d & AUC $(95 \% \mathrm{Cl})$ \\
\hline \multicolumn{5}{|c|}{ Competence as a person $\dagger$} \\
\hline High risk & 65 & $2.70(2.63)$ & 0.58 & $0.68(0.60 ; 0.75)$ \\
\hline Low risk & 607 & $1.17(1.73)$ & & \\
\hline \multicolumn{5}{|c|}{ Competence as a parent $\dagger$} \\
\hline High risk & 84 & $2.01(2.15)$ & 0.37 & $0.62(0.56 ; 0.69)$ \\
\hline Low risk & 589 & $1.22(1.83)$ & & \\
\hline \multicolumn{5}{|l|}{ Childhood experience } \\
\hline High risk & 27 & $5.04(2.00)$ & 1.93 & $0.93(0.91 ; 0.96)$ \\
\hline Low risk & 647 & $1.18(1.74)$ & & \\
\hline \multicolumn{5}{|l|}{ Partner relationship $\ddagger$} \\
\hline High risk & 14 & 3.61 (3.22) & 0.75 & $0.74(0.59 ; 0.90)$ \\
\hline Low risk & 644 & $1.19(1.70)$ & & \\
\hline \multicolumn{5}{|l|}{ Social contactsł } \\
\hline High risk & 47 & $3.71(3.09)$ & 0.83 & $0.76(0.68 ; 0.84)$ \\
\hline Low risk & 628 & $1.15(1.66)$ & & \\
\hline \multicolumn{5}{|c|}{ Depressive symptoms§ } \\
\hline High risk & 58 & $4.11(3.21)$ & 0.95 & $0.81(0.74 ; 0.87)$ \\
\hline Low risk & 610 & 1.07 (1.48) & & \\
\hline
\end{tabular}

Bold numbers indicate a significant difference between the high-risk and low-risk group $(\mathrm{p}<0.008)$ as tested with a Mann-Whitney $U$ test, and corrected for multiple testing with a Bonferroni correction (0.05/6).

*The mean score represents the summation score of the mother.

†Derived from the EMPO 2.0. ${ }^{26}$

†Derived from the Family Functioning Questionnaire. ${ }^{27}$

§Derived from the Parenting Stress Questionnaire. ${ }^{28}$

AUC, area under the curve; EMPO 2.0, Empowerment Questionnaire 2.0; IPARAN, instrument for lentification of Parents at Risk for child Abuse and Neglect.

single parent family, and had a lower net monthly income, compared with the subgroup of parents not at risk

\section{Concurrent validity}

Table 2 shows the correlations between the related constructs and the IPARAN score, separately for mothers and fathers.

The correlations of the IPARAN score of the mother with the related constructs varied from $\mathrm{r}=-0.10$ to $\mathrm{r}=-0.58$ and $\mathrm{r}=0.50$. Of the six pairs analysed, the pairs IPARAN-Competence as a person and IPARAN-Competence as a parent had values of $r$ smaller than -0.30 ; the pairs IPARAN-Partner relationship and IPARAN-Social contacts had values between $r=-0.30$ and $r=-0.49$. And the pairs IPARAN-Childhood experience, and IPARAN-Depressive symptoms had values of $r>0.49$, for both negative and positive correlations. The strongest correlations were found between the IPARAN and the related constructs 'childhood experience' ( $\mathrm{r}=-0.58)$ and 'depressive symptoms' $(\mathrm{r}=0.50)$ (table 2).

Of the six pairs made between the IPARAN score of the father and the related constructs, half of the correlations were not significant $(p>0.05)$ : IPARAN-Competence as a parent, IPARAN-Partner relationship and IPARAN-Social contacts. Of the three remaining significant correlations, the pairs IPARAN-Competence as a person, and IPARAN-Depressive symptoms had an $r$ between 0.30 and 0.49 , for both positive and negative correlations. The pair IPARAN-Childhood experience had an $\mathrm{r}$ of -0.59 , which was also the strongest correlation found (table 2).

\section{Discriminatory power}

Table 3 shows the IPARAN score, the Cohen's $d$ and the AUC for mothers within the borderline/clinical range or lowest 10 percent $(\mathrm{P} 10)$ range of the related constructs (high-risk mothers) and mothers within the normal range or highest 90 percent (P90) range of the related constructs (low-risk mothers). On all related constructs, high-risk mothers had a significantly higher IPARAN score than low-risk mothers $(\mathrm{p}<0.05)$. Half of the effect sizes were large $(\mathrm{d}>0.80)$ and one-third was moderate $(0.50<\mathrm{d}<0.80)$. The ROC curves show that the IPARAN has moderate discriminatory power $(0.70 \leq \mathrm{AUC}<0.90)$ for the related constructs 'depressive symptoms', 'social contacts' and 'partner relationship' and has high discriminatory power $(\mathrm{AUC}>0.90)$ for the related construct 'childhood experience'. For the related constructs 'competence as a person' and 'competence 
as a parent' the IPARAN had low discriminatory power $(0.50 \leq \mathrm{AUC}<0.70) .{ }^{39}$

\section{Feasibility}

The mother's part of the IPARAN had on average $0.7 \%$ missing answers, whereas the father's part of the IPARAN had on average $1.7 \%$ missing answers. The highest percentage of missing answers, for both mothers and fathers, was for the item 'Quarrels with partner ever become physical' (respectively 1.7\% and 2.3\% missing answers). Also, for 32 families $(4.2 \%)$ it was not possible to calculate an IPARAN score for the father/other parent. Only the mothers completed their part and not both parents, despite the mother indicating that she lived together with her husband or partner.

\section{DISCUSSION}

The results of our study suggest that the IPARAN is a valid and feasible tool for assessing risk factors for parenting stress in Dutch parents with a newborn child. The results in terms of feasibility partly confirm the results of an earlier study. ${ }^{20}$

The correlations found between the IPARAN score and those obtained on the related constructs of the EMPO 2.0, ${ }^{26} \mathrm{FFQ}^{27}$ and $\mathrm{PSQ}^{28}$ support the instrument's concurrent validity. Various minor to strong correlations were found between the IPARAN score and the related constructs, filled in by the mother. All directions of the correlations were in line with our expectations. The strongest correlations were found between the IPARAN and the constructs 'childhood experience' and 'depressive symptoms'. The related constructs 'competence as a parent' and 'competence as a person' filled in by the mother showed minor correlations with the IPARAN. A possible explanation for this minor correlation is that the related construct that we chose does not measure exactly the same concept as the IPARAN score with which it is being compared. The items in the IPARAN that are related to competence as a parent focus on worries during pregnancy, about becoming a mother/father, and whether you feel qualified to become a parent, while the related construct focuses more on parenting practices in general. It is likely that the correlation is low due to this conceptual difference.

The correlations for the fathers raise some concern, since half of the correlations were not significant. The related constructs 'competence as a parent', 'social contacts' and 'partner relationship' filled in by the father showed no significant correlation with the IPARAN score of the father. Since our sample size of the fathers was low $(n=51)$, the fact that half the correlations were not significant could be due to this low sample size. We therefore suggest that future research should focus more on the part of the father.

The fact that the IPARAN was able to distinguish between high-risk mothers and low-risk mothers for most related constructs of parenting stress, shows that it has moderate to high discriminatory power. However, it should be noted that the discriminatory power of the IPARAN was low for the related constructs "competence as a person' and 'competence as a parent', findings that were supported by the mean scores and effect sizes. As mentioned above for the concurrent validity, it could be reasoned that the related constructs chosen here do not measure exactly the same concept as measured by the IPARAN. This could explain the low discriminatory power for these particular constructs. In future research, using a different questionnaire for measuring empowerment may help to improve the discriminatory power of the IPARAN.

The IPARAN is a short questionnaire with easily asked and clear questions. The relatively low percentage of missing answers $(\leq 2.0 \%$ for 16 items for both mothers and fathers) supports the feasibility. However, it should be mentioned that for $4.2 \%$ of the families $(n=32)$ in our study it was not possible to calculate an IPARAN score due to the fact that the fathers/other parents did not fill in their part of the IPARAN, while the mother did and had also indicated that she was living together with her partner. This was also seen in a previous study of Bouwmeester-Landweer et al. ${ }^{31}$ Hypothetically, even though it is written above the pages, it may not have been clear for every parent that both parents had to complete a part of the questionnaire. In addition, mothers may have felt uncomfortable having to ask the father to complete their part of the questionnaire. Since these are only hypotheses, we recommend future qualitative research using interviews with fathers and mothers to gain insight into barriers and opportunities they experienced in completing the questionnaire.

The questionnaire is a valuable addition to the default data collected by the YHC, which mainly consists of demographic and basic information like parental age, birth term and birth weight of the child. ${ }^{41}$ With the IPARAN more information is collected on potential risk factors in the family that have been proven to be related to parenting stress, such as the social network of the family ${ }^{46}$ and the developmental history of the parents. ${ }^{4610}$

The concurrent validity, discriminatory power and feasibility show that the questionnaire is easy to use in daily practice of YHC to detect parents at risk of parenting stress. By detecting parents at-risk in time, interventions, such as the Supportive Parenting Intervention, can be offered. Which in turn may prevent consequences of parenting stress on both parent and child health.

\section{Strengths and limitations of the study}

First of all, no data were available on the parents in the large non-response group. Parents were invited directly by professionals working in two YHC during the home visit within 2 weeks after child birth. ${ }^{25}$ Parents who did not want to participate in the study did not complete a questionnaire. We have no insight into reasons for not participating in the study. Second, our sample was largely Dutch with a middle to high educational level. This 
means that the results of our study can only be generalised to this Dutch, highly educated group. Future research should therefore try to include more non-Dutch and lower educated respondents to evaluate the psychometric properties of the IPARAN among these subgroups. Furthermore, we were limited in the instruments that we could administer. Therefore we could not evaluate concurrent validity for the items 'negative sexual experience', 'spousal violence', 'drug/alcohol abuse' and 'belief in physical punishment', as no related constructs were measured in the baseline questionnaire. Since this study was originally set up for measuring empowerment, these constructs were not included. However, these constructs are strong measurements of severe outcomes of parenting stress, such as child abuse and neglect. Therefore we propose that future studies include measurements of related constructs for these items. We also propose that additional psychometric properties (such as test-retest reliability) of the IPARAN be determined in future research. Lastly, we recommend longitudinal research to evaluate the associations between parenting stress (as measured by the IPARAN) and child health and parenting outcomes over time.

Although response rate was not very high, strength of this study is that the sample was nevertheless sufficiently large to allow us to determine the validity and feasibility of the IPARAN. In addition, we used several references (The FFQ, The EMPO 2.0 and the PSQ).

\section{Conclusion}

Our findings that the IPARAN is feasible and shows good concurrent validity and discriminatory power support the use of this instrument. The IPARAN can continue to be used by health practitioners in the Netherlands to evaluate whether parents with a newborn child are at risk of parenting stress. The timeliness of offering preventive help to these parents is vital in order to prevent severe outcomes of parenting stress, such as child abuse and neglect and the long-term harmful effects of child abuse and neglect in these families.

Contributors $\mathrm{HR}, \mathrm{SB}$ and $\mathrm{E} \mathrm{H-dG}$ originated the idea for the study and were responsible for acquiring the grant for the study. MBRB-L invented the intervention. All authors contributed to further develop the study concept and design. $A G$ and $E M B H$ are responsible for data collection, study coordination and reporting study results. EMBH was responsible for drafting and revising the manuscript. CLM, RB, SB, EH-G and MBRB-L contributed to critical revision of the manuscript for important intellectual content. HR is responsible for study supervision and reporting of study results. All authors have read and approved the final manuscript.

Funding This study is funded by grant number $70-72900-98-13137$ by ZonMw, Organization for Health Research and Development, P.0. Box 93 245, 2509 AE The Hague, the Netherlands.

Competing interests None declared.

Patient consent Obtained.

Ethics approval The Medical Ethics Committee of Erasmus Medical Center Rotterdam.

Provenance and peer review Not commissioned; externally peer reviewed.

Data sharing statement № additional data are available.
Open Access This is an Open Access article distributed in accordance with the Creative Commons Attribution Non Commercial (CC BY-NC 4.0) license, which permits others to distribute, remix, adapt, build upon this work non-commercially, and license their derivative works on different terms, provided the original work is properly cited and the use is non-commercial. See: http://creativecommons.org/ licenses/by-nc/4.0/

(c) Article author(s) (or their employer(s) unless otherwise stated in the text of the article) 2017. All rights reserved. No commercial use is permitted unless otherwise expressly granted.

\section{REFERENCES}

1. Reijneveld SA, de Meer G, Wiefferink $\mathrm{CH}$, et al. Parents' concerns about children are highly prevalent but often not confirmed by child doctors and nurses. BMC Public Health 2008;8:124.

2. Belsky J. The determinants of parenting: a process model. Child Dev 1984;55:83-96.

3. Östberg M. Parenting stress. Conceptual and methodological issues. Uppsala: Acta Universitatis Upsaliensis, 1999.

4. Black DA, Heyman RE, Smith Slep AM. Risk factors for child physical abuse. Aggress Violent Behav 2001;6:121-88.

5. Black DA, Heyman RE, Smith Slep AM. Risk factors for child sexual abuse. Aggress Violent Behav 2001;6:203-29.

6. Schumacher JA, Slep AMS, Heyman RE. Risk factors for child neglect. Aggress Violent Behav 2001;6:231-54.

7. Black DA, Smith Slep AM, Heyman RE. Risk factors for child psychological abuse. Aggress Violent Behav 2001;6:189-201.

8. Keuning M, Schulze HJ, Stams GJ, et al. Marital conflict strategies predict child abuse potential in dutch families from low socioeconomic backgrounds. Zeitschrift für Familienforschung 2002;14:153-66.

9. Tajima EA. The relative importance of wife abuse as a risk factor for violence against children. Child Abuse Negl 2000;24:1383-98.

10. Kotch JB, Browne DC, Dufort V, et al. Predicting child maltreatment in the first 4 years of life from characteristics assessed in the neonatal period. Child Abuse Negl 1999;23:305-19.

11. Sidebotham P, Golding J. ALSPAC Study Team. Avon Longitudinal Study of Parents and Children. Child maltreatment in the 'children of the nineties' a longitudinal study of parental risk factors. Child Abuse Negl 2001;25:1177-200.

12. Ertem IO, Leventhal JM, Dobbs S. Intergenerational continuity of child physical abuse: how good is the evidence? Lancet 2000;356:814-9.

13. Hall LA, Sachs B, Rayens MK. Mothers' potential for child abuse: the roles of childhood abuse and social resources. Nurs Res 1998;47:87-95.

14. Brown J, Cohen P, Johnson JG, et al. A longitudinal analysis of risk factors for child maltreatment: findings of a 17-year prospective study of officially recorded and self-reported child abuse and neglect. Child Abuse Negl 1998;22:1065-78.

15. Sidebotham P, Heron J. ALSPAC Study Team. Child maltreatment in the "children of the nineties:" the role of the child. Child Abuse Negl 2003;27:337-52.

16. Lavee $\mathrm{Y}$, Sharlin S, Katz R. The effect of parenting stress on marital quality. an integrated mother-father model. Journal of Family Issues 1996;17:114-35.

17. Mills R, Alati R, O'Callaghan M, et al. Child abuse and neglect and cognitive function at 14 years of age: findings from a birth cohort. Pediatrics 2011;127:4-10.

18. Norman RE, Byambaa M, De R, et al. The long-term health consequences of child physical abuse, emotional abuse, and neglect: a systematic review and meta-analysis. PLoS Med 2012;9:e1001349.

19. Widom CS, Czaja SJ, Bentley T, et al. A prospective investigation of physical health outcomes in abused and neglected children: new findings from a 30-year follow-up. Am J Public Health 2012;102:1135-44.

20. Bouwmeester-Landweer MBR. Early home visitation in families at risk for child maltreatment (Doctoral thesis). Leiden: Leiden University Medical Center (LUMC), Leiden University, 2006.

21. Bouwmeester-Landweer MBR, Kousemaker NPJ, Dekker FW, et al. Home visitation in families at risk for child maltreatment: process-evaluation. Early home visitation in families at risk for child maltreatment. Leiden: Leiden University Medical Center (LUMC), Leiden University;, 2006.

22. Stevig Ouderschap: stevig Ouderschap. https://www. stevigouderschap.nl/voor-professionals/vereniging. 
23. GGD GHOR Kennisnet: ggd GHOR Kennisnet. http://www. ggdghorkennisnet.nl/?file=23239\&m=1433926283\&action=file. download.

24. Landsmeer-Beker EA, Bouwmeester-Landweer MBR, KorbeeHaverhoek HD, et al. Differences between respondents and nonrespondents on a postal questionnaire addressing risk factors for child maltreatment. Bouwmeester-Landweer MBR, ed. Early home visitation in families at risk for child maltreatment. Leiden: Leiden University Medical Center (LUMC), Leiden University, 2006.

25. Horrevorts EM, van Grieken A, Broeren SM, et al. Design of a controlled trial to evaluate the effectiveness of supportive parenting ('Stevig Ouderschap'): an intervention to empower parents at increased risk of parenting problems by providing early home visits. BMC Psychol 2015;3:47.

26. Damen HR, Veerman JW. EMPO Ouders - Versie 2.0. Nijmegen: Praktikon 2011.

27. Veerman JW, Janssen J, Kroes G, et al. Vragenlijst Gezinsfunctioneren - versie voor ouders van jeugdigen van $0 \mathrm{t} / \mathrm{m} 18$ jaar. Nijmegen: Praktikon, 2011.

28. Vermulst A, Kroes G, de Meyer R, et al. Opvoedingsbelasting vragenlijst - versie voor ouders van jeugdigen van $0 \mathrm{t} / \mathrm{m} 18$ jaar. Nijmegen: Praktikon, 2011.

29. von Elm E, Altman DG, Egger $M$, et al.The strengthening the Reporting of Observational studies in Epidemiology (STROBE) statement: guidelines for reporting observational studies. Lancet 2007;370:1453-7.

30. Bouwmeester-Landweer MBR. Risk factors for child maltreatment. early home visitation in families at risk for child maltreatment. Leiden: Leiden University Medical Center (LUMC), Leiden University, 2006.
31. Bouwmeester-Landweer MBR, Dekker FW, Landsmeer-Beker $\mathrm{EA}$, et al. Prevalence of risk factors for child maltreatment in the Netherlands. early home visitations in families at risk for child maltreatment. Leiden: Leiden University Medical Center (LUMC), Leiden University, 2006.

32. Belsky J. Child maltreatment: an ecological integration. Am Psychol 1980;35:320-35.

33. Belsky J. Etiology of child maltreatment: a developmental-ecological analysis. Psychol Bull 1993;114:413-34.

34. Belsky J, Vondra J. Lessons from child abuse: the determinants of parenting. CDC V, ed. Child maltreatment, theory and research on the causes and consequences of child abuse and neglect. Cambridge: Cambridge University Press, 1989.

35. Newberger CM. The cognitive structure of parenthood; the development of a descriptive measure. SRY R, ed. Clinicaldevelopmental psychology New directions of child development: clinical development research. 7. San Francisco: Jossey-Bass, 1980.

36. Baartman HEM. Opvoeden kan zeer doen. over oorzaken Van Kindermishandeling, hulpverlening en preventie. Utrecht: SWP, 1996.

37. CBS. http://www.cbs.nl/nl-NL/menu/methoden/begrippen/default. $\mathrm{htm}$ ?ConceptID=37.

38. Cohen J. Statistical power analysis for the behavioral sciences. New Jersey: Lawrence Erlbaum Associates, 1988.

39. Swets JA. Measuring the accuracy of diagnostic systems. Science 1988;240:1285-93

40. IBM Corp. IBM SPSS Statistics for Windows, Version 21.0. Armonk, NY: IBM Corp, 2012.

41. Wu SS, Ma CX, Carter RL, et al. Risk factors for infant maltreatment: a population-based study. Child Abuse Negl 2004;28:1253-64. 